REVIEWS-LETTERS-REPORTS

\title{
Impact of the fixed and variable component of electricity price on the economic viability of a small-scale photovoltaic power plant
}

\author{
František Janíček, Ján Poničan, Matej Sadloñ ${ }^{1}$
}

\begin{abstract}
The article analyzes electricity prices in Slovakia, their distribution tariff component, and their significant impact on smallscale photovoltaic power plants (PVPs). Fixed part of the distribution tariff component in Slovakia varies considerably, given the region of operation of the distribution system operator as well as the allocated tariff rate. Profitability of the small-scale PVP in Slovakia is widely discussed, with differing opinions of the lay and professional public. The article will explain under what circumstances all the opinions may be true. Profitability predictions available online or done by PVP installers are extremely simplified and lead to misleading results. The existence of fixed and variable components of the price plays a significant role and a simple change of the electricity tariff may bring significant savings and shorten the payback time of the PVP investment. However, this is a complex issue and requires several other factors to be considered, too. The most important ones are the fixed component of the electricity price, household consumption diagram and the distribution system to which the household is connected.
\end{abstract}

Keywords: electricity price, fixed and variable components, prosumer, profitability, optimization, consumption diagram

\section{Introduction}

Decentralized electricity generation may have various forms. In recent years, household renewables are getting more and more popular. There are two main reasons. On one hand they limit the need to use fossil fuels and thus represent a green alternative. On the other hand, decentralization may provide for savings on the household electricity bill. Current Slovak legislation motivates households to install PVPs with a maximum installed capacity of up to $10 \mathrm{kWp}$ [1]. These small sources are not considered for profit and therefore fall under a less strictly regulated regime. The aim of this regulation is to motivate the household towards the utilization of the whole production at the offtake point, ie motivates for self-consumption. The household which decides to invest into the PVP with the aim of producing electricity for its own consumption becomes the so-called prosumer, $i e$ producer and consumer at the same offtake point. Prosumer regulation in the EU member states is not harmonized. There are various regimes. From the perspective of an economic viability, two major regimes can be distinguished, with and without an option to sell the generated electricity at the market. Current Slovak legislation does not allow households to sell electricity. Under these conditions PVP needs to be optimized in the way that the portion of the generated electricity consumed by the household needs to be as high as possible as the unconsumed electricity can only be donated to the electricity supplier in case the household does not have an accumulation system. Optimization can be achieved by adapt- ing the household consumption pattern to the PVP production or by enforcing the PVP with an energy storage system. With the second option, surplus, ie the electricity produced when the PVP production is higher than the household consumption, is stored and may be used at times when the PVP generation is not sufficient. This covers, eg during a cloudy day, evening or at night. However, energy storage is still relatively expensive and, in most cases, significantly decreases the economic viability of an investment into a household renewable installation [2].

The regulatory status quo will be significantly changed with the transposition of the EUs Clean Energy for All Europeans package. It brings many important changes into the legislation of the EU member states. Prosumers right for remuneration being the most relevant for smallscale PVP installations [3]. Introduction of a mandatory remuneration for nonutilized electricity generated by prosumers will have a significant impact on the assessment of the return of investment and will play a major role in the future small-scale PVP optimization. However, it is not clear yet, what form the payment will have and what the level of unit price will be under Slovak conditions. We can predict two main scenarios. The details may solely depend on the wholesale market or the government may opt for an engagement in a form of a support scheme providing some sort of a stable price for all prosumers. However, this will only be decided in the future. Although, the transposition deadline has already passed. So far, Slovak prosumers have had an extra market choice

\footnotetext{
${ }^{1}$ Slovak University of Technology in Bratislava, Faculty of Electrical Engineering and Information Technology, Ilkovičova 3 , 81219 Bratislava, Slovakia, frantisek.janicek@stuba.sk, jan.ponican@stuba.sk, matej.sadlon@stuba.sk
} 
to select an electricity supply tariff provided by one of the market participants, which provided for a surplus electricity remuneration. It has been marketed as a Virtual Battery and could be described as net metering. Simply explained, prosumer sends the surplus into the grid and consequently, at the time of a need, the produced amount of electricity can be virtually taken back and consumed at a reduced price. Price deduction only covers the supply component of the electricity price. All the other price components are still being paid by the prosumer as the grid is still being used.

\section{Electricity price components}

To define the value of the PVP generated electricity, it is necessary to understand the structure of the final electricity price. Household electricity consumers in Slovakia periodically receive a regular invoice listing all the electricity price items. The final or integrated electricity price for households is calculated per $1 \mathrm{kWh}$ of electricity consumed, including taxes. The price includes all individual components, ie supply, retail, distribution and other charges. Based on the 2020 data published by Eurostat, the final electricity price for households in Slovakia was approximately $0.1689 € / \mathrm{kWh}$, as shown in Fig. 1, [4].

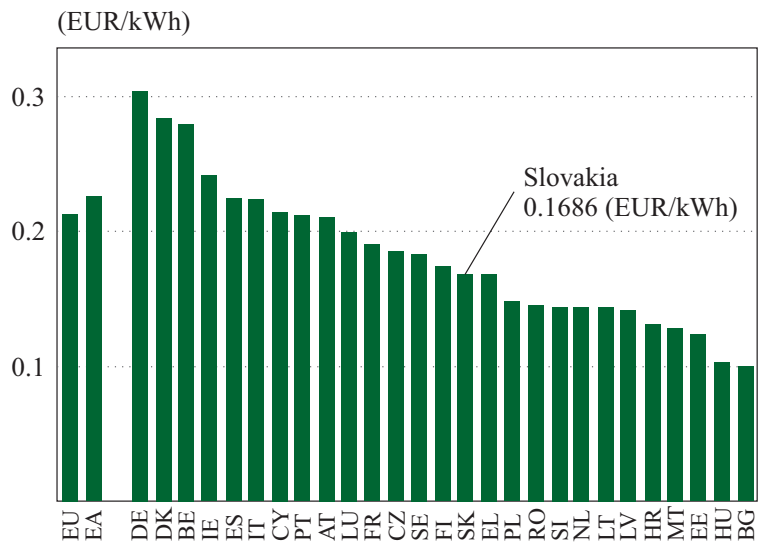

Fig. 1. Electricity prices for household costumer, first half 2020

The final electricity price for household customers consists of the following components [5]:

- fixed and variable electricity supply component,

- fixed and variable distribution component,

- distribution losses charge,

- system operation charge (TPS),

- system services charge (TSS),

- National Nuclear Fund charge,

- value added tax.

The electricity price for households in Slovakia is not deregulated. Its calculation is regulated and subject to proceedings before the Regulatory Office for Network Industries. The National Nuclear Fund charge and the value added tax are set by specific laws. All the other components are regulated by the Regulatory Office. The only exception is the electricity supply component, which still is a subject to price cap decided upon by the Regulatory Office based on the evolution of wholesale electricity prices. In the context of the market liberalization, suppliers can only compete in terms of the electricity supply component of the price, as all the other components are strictly regulated and same for all the suppliers. Each of the components, except for tax, is connected to a unit of measure $\mathrm{kWh}$ or month depending on the character of the component, ie whether it is fixed or variable.

The structure of the final electricity price for households in Slovakia is shown in Fig. 2, [5]. It shows that the supply component accounts for only around $36 \%$ of the total electricity payment. Significant part of the price is represented by the system operation tariff, which provides finances for a state support scheme for electricity generated from renewables, cogeneration of electricity and heat, as well as for production of brown coal electricity in the Nováky-Handlová region.

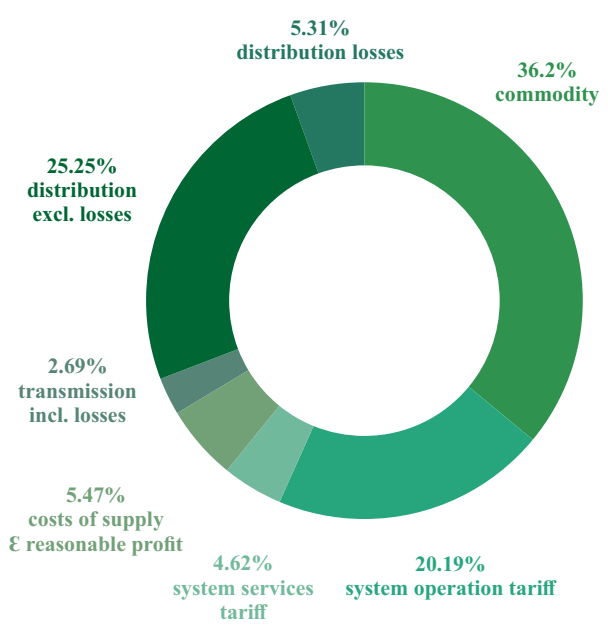

Fig. 2. Breakdown of electricity price for households

Both supply and distribution components are made up of a fixed and variable elements Fixed elements are paid regardless of the amount of electricity consumed. They represent a monthly flat rate for supply or distribution of electricity and usually depend on the character of the offtake point. The fixed element of the supply component should represent fixed costs of the suppliers business activity. The fixed element of the distribution component represents a charge for an access to the distribution system and a reserved capacity related to the consumption at the offtake point.

The final price for a particular household may be significantly different from the average final price, given the tariff type applied. The number of tariff types in Slovakia varies, depending on the distribution system the final consumer is connected to. Tariff type represents the curve type of the consumption diagram typical for the group of consumers. Tariff is selected based on ex-ante defined conditions of the demand for electricity supply. In general, tariff rates can be categorized, depending on the expected consumption diagram, into: 
Table 1. Fixed and variable distribution fees for various tariffs under all DSOs in Slovakia

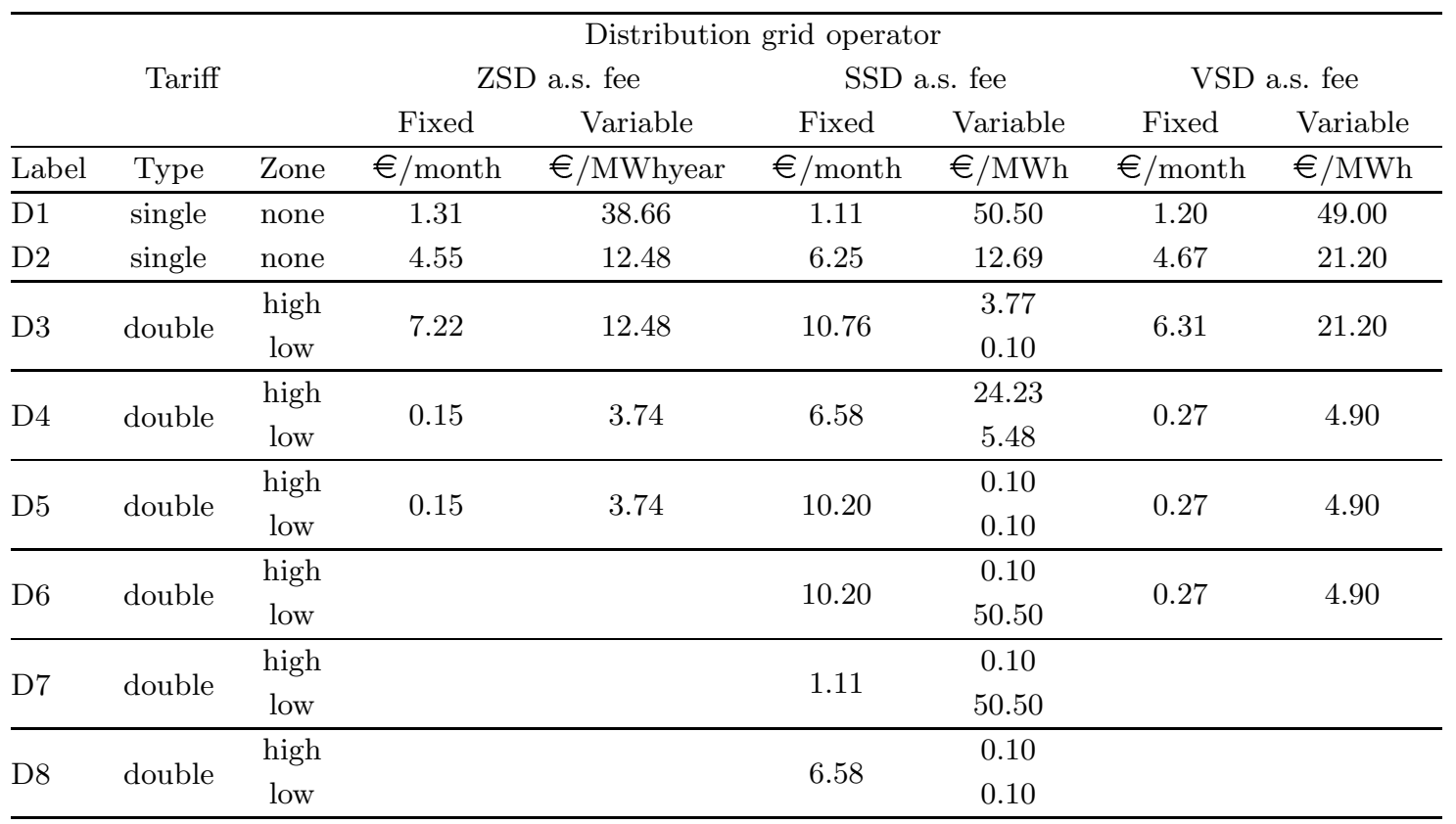

- single tariff with low consumption,

- single tariff with higher consumption,

- double tariff with demand-side management with fixed low tariff (LT) and HT bands,

- double tariff with demand-side management with operatively managed LT for hot water heating and accumulation heating,

- double tariff with demand-side management with operatively managed LT for direct heating and heat pumps.

Tariff types of each distribution system operator slightly vary. The price list of each operator includes a tariff name, tariff description, subscription conditions and recommended household characteristics. In addition, the double tariff for households with electric heating has a specifically defined ratio of the total electricity consumption in the low and high band that must be respected to be eligible for the subscription. Household tariffs in Slovakia are generally indicated by letter D, eg D1, D2, D3, etc. Tariffs for businesses are often indicated by letter C, eg C1, C2, C3, etc. Distribution grid operator in central Slovakia provides a specific tariff for holiday houses.

Each tariff type includes a fixed and a variable element for both supply and distribution component of the price. Table 1 shows the household price of the distribution component. Supply component is not shown in the table as their variable elements are only regulated by a price cap and thus vary among the suppliers. Conversely, distribution fees are fully regulated and separately approved for each of the regional distribution grid operators based on their costs. The following prices are in force from 1 January 2021 [6-8].
The distribution fee covers transmission losses. This may seem to be confusing as the Regulatory Office keeps the distribution losses as a separate item. On the other hand, the Regulatory Office defines the structure of the final electricity price for households in a way that the transmission losses charge is included in the distribution fee and only the distribution losses charge is listed separately. Distribution losses charge is calculated based on the voltage level. Naturally, the higher the fee the lower the voltage level.

Charges marked with an index $(*)$ are defined according to the ampere value of the main circuit breaker and the number of phases of the electrical connection. Their calculation is based on formula $F_{\mathrm{FIX}}=n V_{\mathrm{CB}} \times 0.15$. Table 1 shows that only some of the tariffs are based on these characteristics.

Only the Distribution System Operators (DSOs) in western and eastern Slovakia base some of their tariffs on the main circuit breaker amperage value. These tariffs cover those intended for accumulation heating (D4), direct heating (D5) and heat pumps (D6). All the other tariffs' distribution fees are set regardless of the size of the main circuit breaker. Fixed monthly fee calculation for households in the region of the western DSO is given as above while in the eastern region formula $F_{\mathrm{FIX}}=V_{\mathrm{CB}} \times 0.2705$ is applied. Hhere, $\left.F_{\mathrm{FIX}}\right)$ is monthly fixed distribution fee, $n$ represents number of phases (1 or 3 ) and $V_{\mathrm{CB}}$ is value of main circuit breaker in amperes.

Table 1 shows significant differences between the fixed and variable elements of the individual tariffs. This is most visible in case of the SSD a.s. (central Slovakia) DSO. Its double tariffs D5, D6 and D8 are almost entirely based on a fixed distribution fee, while the variable element is minimal. Thus, the distribution component in 
Table 2. Fixed distribution fees for various tariffs under all DSOs in Slovakia

\begin{tabular}{ccccccc}
\hline \multirow{2}{*}{ Tariff } & \multicolumn{2}{c}{ Zistribution grid operator } \\
& Fixed & Anual & Fixed & Anual & Fixed & Anual \\
\hline Label & $€ /$ month & $€ /$ year & $€ /$ month & $€ /$ year & $€ /$ month & $€ /$ year \\
\hline D1 & 1.31 & 18.91 & 1.11 & 15.98 & 1.20 & 17.28 \\
D2 & 4.55 & 65.91 & 6.25 & 90.00 & 4.67 & 67.24 \\
D3 & 7.22 & 103.95 & 10.76 & 154.94 & 6.31 & 90.86 \\
D4 & $0.15^{*}$ & 162.00 & 6.58 & 94.75 & $0.27^{*}$ & 97.38 \\
D5 & $0.15^{*}$ & 162.00 & 10.20 & 146.88 & $0.27^{*}$ & 97.38 \\
D6 & & & 10.20 & 146.88 & $0.27^{*}$ & 97.38 \\
D7 & & & 0.11 & 15.98 & & \\
D8 & & & 6.58 & 94.75 & & \\
\hline
\end{tabular}

*included VAT

case of these tariffs is almost completely dependent on the flat rate. The variable basically negligible, ie fees will be almost completely independent of the amount of electricity consumed by the household. These tariff rates are intended for households with electric heating. As electricity heating is much more energy intensive compared to electricity consumption for other purposes, the distribution tariff is designed in a way that would motivate households to consume large amounts of electricity for heating, ie the variable component of the electricity distribution fee is minimal. D5 is intended for households with direct heating and has an operative control of a 20 hours a day low tariff (LT). D6 is intended for households with a heat pump and is based on an operative control of a 22 hours a day LT. D8 is intended for households with storage heating and has an operative control of an 8 hours a day LT. It is important to state that households allocation under one of these tariffs requires meeting several technical conditions and their fulfilment must be proven by a technical check [6-8].

This is however not the case for tariffs D1, D2 and D3 as these do not require meeting specific conditions. On the other hand, tariffs D4, D5, D6 and D8 require meeting several conditions related to an automatic control of certain types of electrical appliances, size of the installed capacity of heating appliances, remote control, and ratio of annual consumption in high and low tariff bands. This means that Slovak households are not completely free to select the tariff of their choice.

The above-mentioned observations have a significant impact on the economic viability of the small PVPs. As it was discussed, distribution component of the final price plays a key role here and thus will be in the center of this Article. PVP optimization needs to consider the impact of the fixed component of the electricity distribution price on the profitability of the PVP as such.

Distribution fees under Slovak conditions consist of 3 components. These are the distribution charge, distribution losses charge and transmission and transmission losses charge. As mentioned above, the distribution losses charge is a separate purely variable billing item and thus not of an interest when evaluating the PVP profitability. Conversely, the distribution and transmission charges, including transmission losses, are usually displayed in the bill as a single price component, ie the distribution charge, and has both fixed and variable components. Figure 2 shows that the so-called distribution component represents approximately $28 \%$ of the average household electricity price in Slovakia. As discussed above, the ratio between its fixed and variable components significantly differs for each tariff. The major example being the central Slovakia DSO with D5, D6 and D8 tariffs.

Households' annual fixed distribution charges are shown in Table 2. They were calculated as the product of the monthly charge and the number of months in a year plus a $2 \%$ value added tax. For the ZSD a.s. (western) and VSD a.s. (eastern) DSOs tariffs D4, D5 and D6, the annual fixed charge was based on the value of the main circuit breaker $325 \mathrm{~A}$, according to above given formulae.

\section{Metodology}

Recent study analyzing the profitability of household PVPs concluded that in order to decrease their payback periods it is essential to maximize the real-time consumption of the PVP generated electricity as the accumulation of electricity surpluses is currently unprofitable in Slovak conditions [9]. However, a full compliance of the instantaneous PVP production and households consumption is almost impossible to achieve in practice. Devices capable of control over the performance of selected electrical equipment are therefore very relevant [2], [10].

Comprehensive financial analysis requires simulations [9,11]. Mathematical model is based on households' consumption data extracted from two sources. First being smart metering systems of various households, second being the typical consumption diagrams, which are widely used by the Slovak market participants. Simulations are 
Table 3. Annual fixed distribution fees and savings per kWh of utilized PVP generated electricity for various tariffs under all DSOs in Slovakia

\begin{tabular}{ccccccc}
\hline \multirow{2}{*}{ Tariff } & \multicolumn{5}{c}{ ZSD a.s. fee } & \multicolumn{2}{c}{ SSD a.s. fee } & \multicolumn{2}{c}{ VSD a.s. fee } \\
& Anual & PVP & Anual & PVP & Anual & PVP \\
& fixed* & savings & fixed* & savings & fixed* & savings \\
\hline Label & $€ /$ year & $€ / \mathrm{kWh}$ & $€ /$ year & $€ / \mathrm{kWh}$ & $€ /$ year & $€ / \mathrm{kWh}$ \\
\hline D1 & 18.91 & 0.164 & 15.98 & 0.165 & 17.28 & 0.165 \\
D2 & 65.91 & 0.152 & 90.00 & 0.146 & 67.24 & 0.146 \\
D3 & 103.95 & 0.143 & 154.94 & 0.130 & 90.86 & 0.130 \\
D4 & 162.00 & 0.117 & 94.75 & 0.145 & 97.38 & 0.145 \\
D5 & 162.00 & 0.117 & 146.88 & 0.132 & 97.38 & 0.132 \\
D6 & & & 146.88 & 0.132 & 97.38 & 0.132 \\
D7 & & & 15.98 & 0.165 & & \\
D8 & & & 94.75 & 0.145 & & \\
\hline
\end{tabular}

*included VAT

based on hourly PVP production predictions and households hourly consumption data and result in an amount of electricity that can be utilized by the household. These calculations were carried out for 3 major PVP utilization scenarios. These include real time consumption, battery accumulation and a subscription to a supplementary market service in the form of net metering. The total amount of the electricity utilized by households was reflected in a financial analysis, which compared the impacts of the distribution components of various tariffs of all three Slovak regional distributors on the economic viability of the investment. In other words, results show a clear comparison of impacts various distribution tariffs have on the profitability of the households' PVPs.

It is important to understand that an on-grid prosumer without an energy accumulation system uses the grid electricity in periods when the power provided by the PVP is insufficient to meet the consumption. Under those circumstances the only option is to buy the electricity from the supplier at a household electricity price. Moreover, even in periods with a sufficient PVP production, the fixed component of the distribution charge needs to be paid as it paid monthly regardless of the consumption. The rationale is represented by the capacity that was reserved for the offtake point. As a result, we can conclude that the PVP produces electricity that is reflected in price savings equal to a final electricity price deducted by the fixed component of the distribution price, which always needs to be fully paid, ie cannot be saved even if the whole consumption would be covered by the PVP production

$$
S_{\mathrm{PVE}}=\frac{c_{\mathrm{VAR}}-\frac{c_{\mathrm{VAR}} \Delta E}{E}}{E_{\mathrm{FVE}}} .
$$

Here, $S_{\mathrm{FvE}}$ represents savings per kWh of utilized PVP electricity, $c_{\mathrm{VAR}}$ is the variable component of the annual electricity bill, $\Delta E$ denotes the annual grid electricity consumption, $E$ is annual electricity consumption and $E_{\mathrm{FVE}}$ stands for annual amount of utilized PVP electricity.

The formula shows that savings resulting from the consumption of the electricity generated by the PVP depend on the character of the household, its annual electricity consumption and on the proportion of the PVP generated electricity that can be utilized by the household. As it was stated above, fixed component of the electricity price must be paid regardless of the amount of consumed grid electricity. Therefore, the formula calculating savings needs to reflect only the variable component of the electricity price. The variable costs are given as a difference between the total annual electricity bill and the annual fixed distribution charge. Savings also need to consider the portion of the PVP generated electricity cannot be utilized by the household, because this energy is only donated to the supplier and thus does not have a financial value for the household. The annual utilized PVP generated electricity therefore represents the amount of electricity that was generated by the PVP and consequently consumed by the household by means of electrical its appliances or was stored in an energy accumulator. It is important to mention here that the surplus electricity may have a financial value for the household in case it would be subscribed to an extra service provided by its electricity supplier. Above mentioned Virtual Battery service provides for a net metering, which benefits the prosumer with a partial remuneration for its electricity surplus. The bottom line is that current Slovak regulation and market situation does not provide prosumers with surplus remuneration or if it does it is almost negligible. For this reason, savings are almost entirely based on the amount of PVP generated electricity that can be utilized in a real time or accumulated and used later.

Formula (3) was used for savings calculation for selected prosumers from all currently available tariff rates and for all 3 DSOs. Savings calculated for a prosumer 
Savings of utilized PVP electricity $(€ / \mathrm{kWh})$

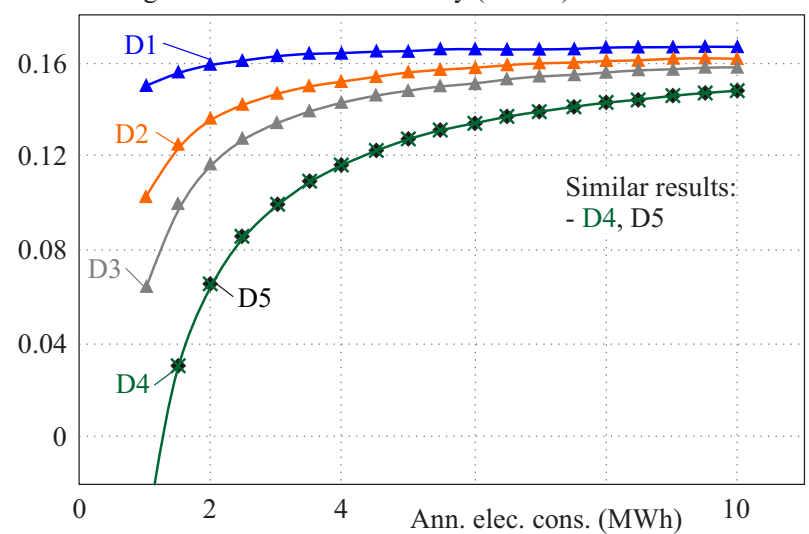

Fig. 3. Savings per kWh of utilized PVP generated electricity for various tariffs under western DSO

Savings of utilized PVP electricity (€/kWh)

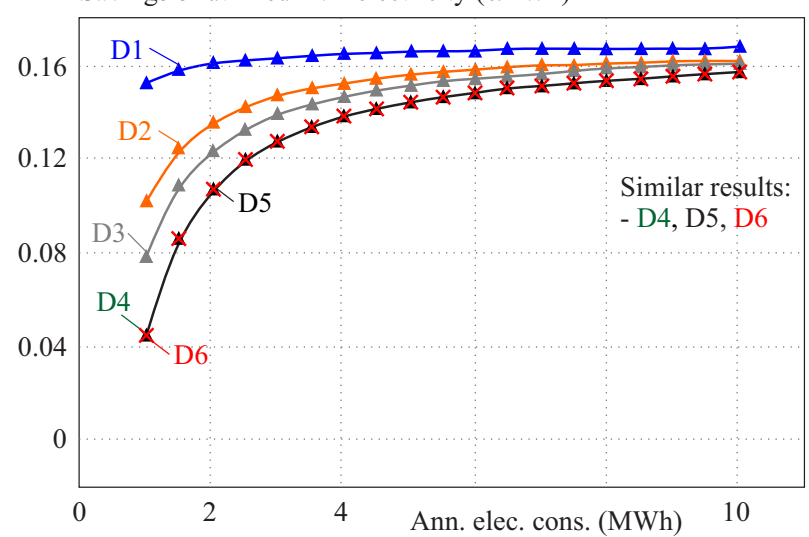

Fig. 5. Savings per kWh of utilized PVP generated electricity for various tariffs under eastern DSO

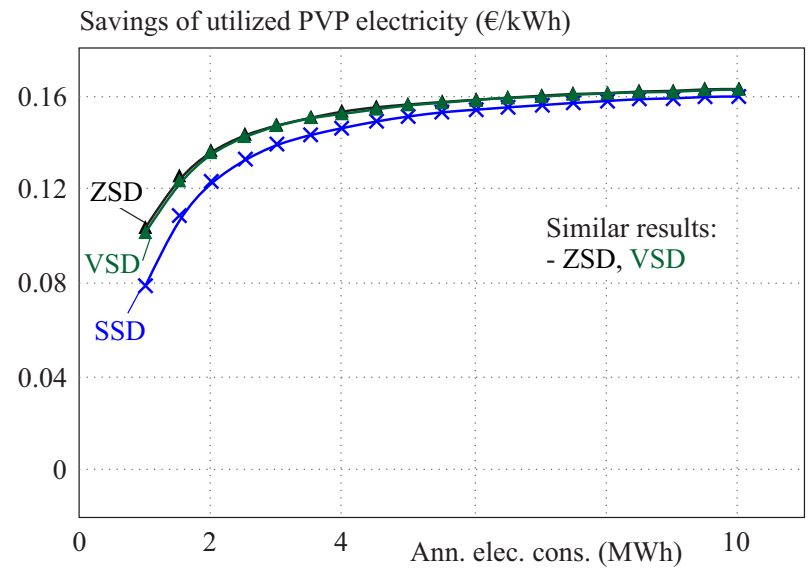

Fig. 7. Savings per kWh of utilized PVP generated electricity for tariff rate $\mathrm{D} 2$

with an annual electricity consumption of $4000 \mathrm{kWh}$ are displayed in Tab. 3. The table also shows the applicable annual fixed fees for electricity distribution.

Savings calculation requires several inputs. These are annual electricity consumption, annual PVP production and annual amount of PVP generated electricity utilized by the household. The data can be obtained either from a historic PVP operation, or, if the PVP has not yet been

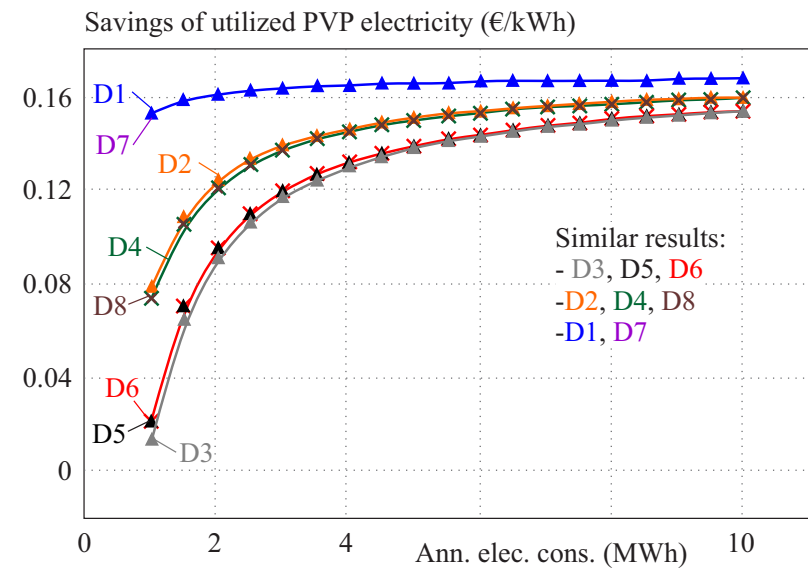

Fig. 4. Savings per kWh of utilized PVP generated electricity for various tariffs under central DSO

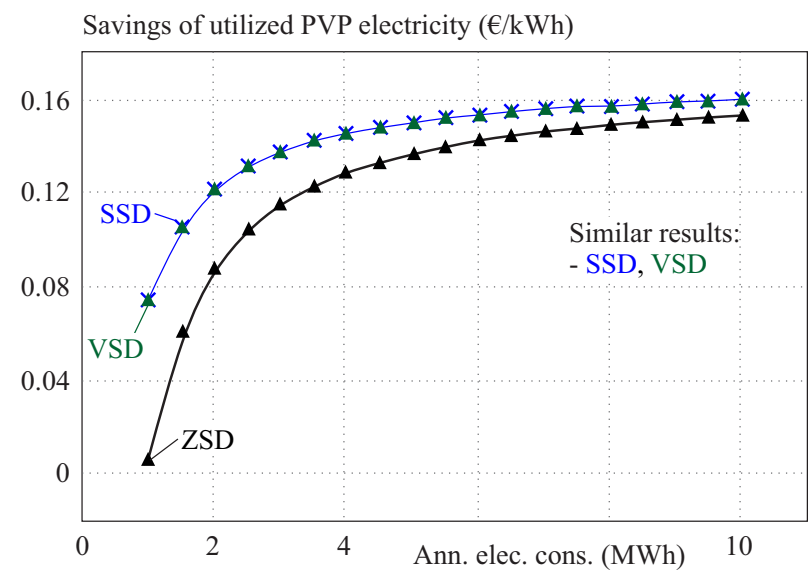

Fig. 6. Savings per kWh of utilized PVP generated electricity for tariff rate $\mathrm{D} 4$

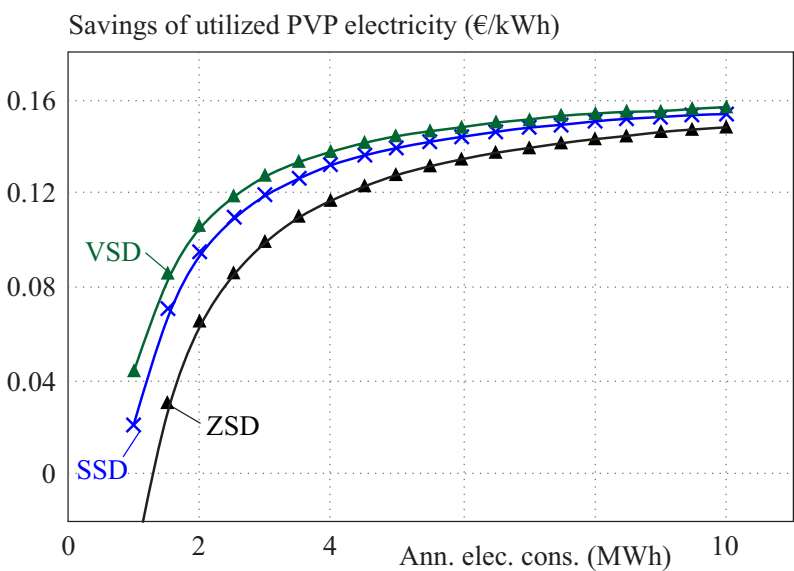

Fig. 8. Savings per $\mathrm{kWh}$ of utilized PVP generated electricity for tariff rate $\mathrm{D} 5$

installed, a simulation model can be used. Model is based on hourly values of PVP production and hourly values of households consumption extracted either from a smart metering system, or a typical consumption diagram. The annual amount of PVP generated electricity utilized by the household covers both the real time consumption and the amount of electricity accumulated in the storage system. 
Variable annual costs may be based on the billing data of a specific prosumer. This approach will lead to accurate results for a specific household. To achieve more general results, this Article was based on an average final price of electricity for households published by Eurostat, ie 0.1686 $€ / \mathrm{kWh},[4]$.

\section{Findings}

For analysis to be as broad as possible various households are assessed. Article compares prosumers with annual electricity consumption in the range of $1 \mathrm{MWh}$ to 10 MWh for all 3 Slovak regional DSOs. Results are displayed in Fig. 3, 4 and Fig. 5.

Figures in question clearly show several important findings. The fundamental one being the rule that higher the annual electricity consumption, higher the savings per $\mathrm{kWh}$ of PVP generated utilized electricity. This is naturally caused by the fact that the ratio between fixed and variable charge of the bill is increasing in favor of the variable component with an increase in the consumption. Fixed component is dominant mostly in case of low consumption levels. This effect is enforced by a subscription to one of the heating tariffs as these usually have a higher fixed charge. Hence, savings resulting from the consumption of a self-generated electricity will be very low especially for households with electricity heating tariffs and low consumption levels. Their investment into the PVP cannot be assessed as economically viable. A typical example being a family house with an electric boiler for domestic water heating. In case its annual consumption would be $4 \mathrm{MWh}$ and prosumer would be connected to the western DSO under tariff D4, savings would represent only $128 € /$ MWh. Level of savings would be approximately $24 \%$ lower than the average final price of electricity. This may lead to unrealistic payback period predictions caused by a significant inaccuracy in the calculations as these are often based on average electricity price.

Graphs show relatively significant differences in the savings per $\mathrm{kWh}$ of utilized PVP generated electricity. Differences do not arise only from different consumption amounts, but also from different tariff rates. Small-scale PVPs are relevant mostly for family houses rather than apartments and blocks of flats. Family house are usually subscribed to tariffs D2, D4, D5 and D6 based on their specific characteristics. Another important finding is that differences are visible also when comparing the same tariff groups with similar consumptions connected to different DSOs. Figure 6 compares savings of a D4 prosumer connected to grid under all three DSOs. This prosumer connected to the western distribution grid is significantly disadvantaged compared to the same one in central or eastern Slovakia. An average D4 household consuming approximately $4 \mathrm{MWh}$ of electricity annually would have approximately $11 \%$ lower savings from their PVP with a level of $128 € \mathrm{MWh}$. The same prosumer would have savings of $0.144 €$ per $\mathrm{kWh}$ in both central and eastern region. Similar differences can be seen for tariff rates D2 and D5. These are displayed in Fig. 7 and Fig. 8.

\section{Conclusion}

The major conclusion drawn on the above-mentioned findings is that savings made by the utilization of selfgenerated electricity will never have equal value to the price of the grid electricity. This is related to the fact that the electricity price has both variable and fixed components and the fixed component is paid regardless of the amount produced by the PVP. The second important point is that the current strictly regulated tariff structure in Slovakia does not provide household customers with a wide room for selection. Once the household has a specific appliance installed, such as electrical heating system, electrical boiler or heat pump, it does not really have many options when choosing the tariff. Therefore, it might end up with a tariff rate which will in connection with its electricity consumption be unprofitable from the point of view of their PVP investment.

The second important point is that the current strictly regulated tariff structure in Slovakia does not provide household customers with a wide room for selection. Once the household has a specific appliance installed, such as electrical heating system, electrical boiler or heat pump, it does not really have many options when choosing the tariff. Therefore, it might end up with a tariff rate which will in connection with its electricity consumption be unprofitable from the point of view of their PVP investment. The third finding is that the ratio between the fixed and variable price components is significantly different not only among different tariffs, but also among the distribution grids. Good example being a prosumer with D5 tariff, intended for direct heating, with an ampere value of the main circuit breaker of $3 \times 32 \mathrm{~A}$. Fixed distribution fee for this type of household connected to the western distribution grid is $207 €$ per year, while the same household in the eastern Slovakia would only pay $124 €$ per year. The difference would extend the payback period by approximately $15 \%$. The analysis concludes that in some cases it is possible to increase the PVP savings by changing the tariff rate. Usually, the aim should be to decrease the fixed fee. In current Slovak conditions higher the tariff rate hire the fixed and lower the variable fee. However, decreasing the fixed fee does not always have to be economically justified. An example would be a household with an electric heating, respective tariff rate and relatively small PVP. As it has a high consumption and majority of its electricity demand is still covered by the grid electricity, lower variable charge is more relevant than a lower fixed charge. Naturally, fixed distribution fees are generally higher for heating tariffs, as it is assumed that the annual electricity consumption will be much higher with the electricity heating. On the contrary, there are many households subscribed to these tariffs as they have an electricity heating system, but they usually use an alternative heating source, such as a biomass. This leads 
to a situation when their fixed charge is relatively high compared to the variable component of the bill. And this is one of the cases that leads to a disproportionately low savings when using PVP. Indeed, each prosumer has a chance to request for a transfer to another tariff group. However, transfer would only be allowed if the prosumer sufficiently demonstrates a change in the behavior. Relevant example would be an electrical installation reconstruction, after which there would be no further use of the electric heating appliances. However, even this change would not always be financially relevant, as it still may lead to unsuitable fixed distribution fees in some cases.

The most significant increase in savings can be achieved by a transition from D3 or D4 to D1 or D2 rates in western Slovakia. This switch would mean an increase in savings from a level of $0.117 € / \mathrm{kWh}$ to approximately $0.152 € / \mathrm{kWh}$, ie an economic benefit of $29.9 \%$. For households with both PVP and DHW electric appliances the optimal scenario covers a smart DHW preparation linked with a real-time PVP output.

Prosumers with lower annual consumptions, ie up to 4 MWh, have the highest savings from their utilized PVP generated electricity when subscribed to tariff D1. D2 consumer should request for a transfer to D1 after installing a PVP to achieve lower fixed distribution fees. This is also justified by the fact that own electricity production will cause a decrease in grid electricity consumption. Good example being such a prosumer with an annual electricity consumption at 2.5 MWh located in the western Slovakia. Switching to D1 would increase savings by approximately $12 \%$, ie from the original $0.142 € / \mathrm{kWh}$ under D2 tariff to $0.161 € / \mathrm{kWh}$ under D1 tariff.

However, the final conclusion is that each prosumer should be assessed individually. The analysis should be tailor-made and should reflect households annual consumption, PVP production and the share of the electricity that can be utilized. It is extremely difficult to formulate a general conclusion. All the above-mentioned findings represent general principles that should be reflected by both the PVP installers and consumers. The PVP optimization should be based on these principles as they can significantly affect the payback period of the investment and thus contribute to the positive economic and environmental benefits of using local renewable resources.

\section{Acknowledgements}

This publication was created thanks to support under the Operational Program Integrated Infrastructure for the project: International Center of Excellence for Research on Intelligent and Secure Information and Communication Technologies and Systems 2nd stage, ITMS code: 313021W404, co-financed by the European Regional Development Fund.

\section{REFERENCES}

[1] Act No. 251/2012 Z. z. z from 31 July 2012 (O energetike a o zmene a doplnení niektorých zákonov), § 2 (in Slovak).
[2] R. Luthander, J. Weidn, and D. Nilsson, "Photovoltaic self-consumption in buildings: A review", Applied Energy, vol. 142, 15, pp. 80-94, 2015.

[3] "Directive (EU) 2019/944 of the european parliament and of the council of 5 june 2019 on common rules for the internal market for electricity and amending directive 2012/27/EU, Article 15",.

[4] 04.03.2019 "Electricity price statistics, Eurostat", https://ec .europa.eu/eurostat /statistics-explained/index.php/Electricity _price_statistics [04.03.2019].

[5] 04.03.2019 "Breakdown of electricity price for households", Regulatory office for network industries, http://www.urso.gov .sk/sites/default/files/ dokumenty/Report_2019_EN_10.pdf [04.03.2019].

[6] "Ruling No. 0110/2021/E from 23. 12. 2020", Regulatory office for network industries,19-22,(in Slovak).

[7] "Ruling No. 0112/2021/E from 28. 12. 2020", Regulatory office for network industries, pp.24-26, (in Slovak).

[8] "Ruling No. 0111/2021/E from 23. 12. 2020", Regulatory office for network industries, p.26-27.

[9] F. Janíček, J. Poničan, and M. Sadloň, "Modified discounted payback period of various small-scale photovoltaic installations", Elektroenergetika 2019: 10th International scientific symposium on electrical power engineering, Stará Lesná, Slovakia, September 16-18, 2019, ISBN 978-80-553-3324-3.

10] M. G. Fikru, G. Gelles, A. M. Ichim, and M. J. Zawodniok, "An economic model for residential energy consumption, generation, storage and reliance on cleaner energy", Renewable Energy, vol. 119, April 2018, pp. 429-438.

[11] A. Chaianong, S. Tongsopit, A. Bangviwat, and Ch Menke, "Bill saving analysis of rooftop PV customers and policy implications for Thailand", Renewable Energy, vol. 131, February 2019, pp.422-434.

Received 17 February 2021

František Janíček (prof, Ing, PhD) was born in 1954. He is director of the Institute of Power and Applied Electrical Engineering at the Faculty of Electrical Engineering and Information Technology of the Slovak University of Technology in Bratislava. His research is focused on electrical protections, power stations, substations, energy problems and renewable energy sources.

Ján Poničan (Ing) was born in 1993. He graduated from the Faculty of Electrical Engineering and Information Technology of the Slovak University of Technology in 2018. He is currently a doctoral student at the Institute of Electrical Power Engineering and Applied Electrical Engineering FEI STU. His research is focused on renewable energy sources such as photovoltaic power plants for households in Slovakia. It deals with their optimization taking into account current legislative measures. He is working on the creation of a computational model of photovoltaic power plants for prosumers.

Matej Sadloň (Mgr) was born in 1992. His research focuses on EU policy and its impact on electricity markets. Matej studied law at Comenius University in Bratislava and completed foreign study stays at the Stockholm University and the University of Bergen. His studies covered various aspects of energy law and policy. His current enrolment at the Faculty of Electrical Engineering and Information Technology of the Slovak University of Technology in Bratislava examines the development of the Slovak electricity market under the introduction of competition rules, decentralization and other novel policies. 